\title{
Orçamento Democrático Estadual: uma estratégia para gestão pública
}

\author{
Rômulo Leite Amorim' \\ Universidade Federal do Rio Grande do Norte \\ Vânia de Vasconcelos Gico ${ }^{2}$ \\ Universidade Federal do Rio Grande do Norte
}

Artículo de Reflexión derivado de Investigación

Recibido: Agosto 28 de 2016 Aprobado: Noviembre 09 de 2016

\section{Resumo}

Discute-se como vem sendo elaborada uma nova estratégia de planejamento no Estado da Paraíba, envolvendo a participação da sociedade civil. Aponta-se como objetivo: verificar qual a estratégia de gestão que se desenvolve na Paraíba e quais os princípios que norteiam o Orçamento Democrático Estadual? Desenvolve-se como aporte teórico as teorias sobre a democracia defendida por Avritzer, sobre participação, descentralização e sociedade civil em Dagnino e Jacobi, bem como as teorias da administração de Trigueiro, Costin, e Kanaane. $O$ estudo realizado permitiu compreender que o Planejamento Estratégico elaborado pelo Governo do Estado da Paraíba, modifica a visão tradicional da administração pública, ao incentivar e criar um instrumento de participação da sociedade na discussão das leis orçamentárias. Por fim, através do caso referenciado, vislumbra-se como a democracia participativa enquanto instituição política pode interferir na vida do Estado, mudando sua organização e seu modo de agir em relação aos cidadãos e cidadãs.

Palavras-chave: Orçamento Democrático Estadual-PB. Democracia Participativa- PB. Planejamento Estratégico Estadual- PB.

\footnotetext{
I Docente do Instituto Federal de Educação, Ciência e Tecnologia da Paraíba - IFPB. Discente do Programa de Pós-Graduação em Ciências Sociais da Universidade Federal do Rio Grande do Norte (PGCS/UFRN).

Endereço eletrônico: amorimromulo@gmail.com

2 Docente do Programa de Pós-Graduação em Ciências Sociais da Universidade Federal do Rio Grande do Norte (PGCS/UFRN). Endereço eletrônico: vaniagico@gmail.com
} 


\title{
Budget of the democratic state: a strategy for public management
}

\begin{abstract}
An analysis is presented of how a new planning strategy has been developed in the state of Paraiba, with the participation of civil society. The objective is to verify what has been the management strategy developed in Paraiba and the principles that rule democratic provincial budget. As a theoretical contribution, Avritzer's theory of democracy, Dagnino's and Jacobi's theory of participation, decentralization and civil society, and Tariq's, Costin's and Kanaane's theory of administration are developed.

The study allowed us to understand that the strategic plan prepared by the Government of State of Pariba changes the traditional point of view of public administration, to foment and create a participation tool society in the discussion of budget law. Lastly, through the reference case, it is apparent how participative democracy as political institution can interfere in the life of the State, changing its organization and mode of action in relation with the citizens.
\end{abstract}

Key words: Provincial democratic budget, Participative democracy, Provincial strategic planning.

\section{Presupuesto del estado democrático: una estrategia para la gestión pública}

\section{Resumen}

Se analiza cómo se ha desarrollado una nueva estrategia de planificación en el estado de Paraiba, con la participación de la sociedad civil. Se señala como objetivo verificar cual ha sido la estrategia de gestión que se ha desarrollado en Paraíba y los principios que rigen el presupuesto democratico provincial. Se desarrolla como aporte teórico las teorías de Avritzer sobre la democracia, de Dagnino y Jacobi sobre la participación, descentralización y sociedad civil y de Tariq, Costin y Kanaane, sobre la administración.

El estudio permitió entender que el plan estratégico elaborado por el Gobierno del Estado de Paraiba, cambia el punto de vista tradicional de la administración pública, para fomentar y crear una sociedad con la herramienta de la participación en la discusión de la ley de presupuestos. Por último, a través del caso de referencia, se ve como la democracia participativa como institución política puede interferir en la vida del Estado, cambiando su organización y modo de acción en relación con los ciudadanos.

Palabras clave: Presupuesto Democrático Provincial- PB. Democracia Participativa- PB. Planificación Estratégica Provincial- PB. 


\section{Gestão pública e estratégica: orçamento democrático estadual}

Ocidente, ao longo do século $X X$, foi marcado pelo constante estabelecimento de novos regimes políticos, fato que fez florescer diversas discussões acerca do lugar que a democracia deveria ocupar nas sociedades ocidentais. Percebe-se que tais debates em torno do modelo democrático a ser implantado pelos países ocidentais tiveram início, sobretudo, logo após o término dos grandes conflitos mundiais, em 1914-1918, a Primeira Guerra Mundial e em 1939-1945, a Segunda Guerra Mundial.

Nesta busca pela institucionalização da democracia como forma de governo, verifica-se que novas concepções surgiram, sendo que algumas se tornaram hegemônicas, enquanto outros modelos apenas serviram de parâmetro para o estabelecimento dos diversos tipos de democracia, que foram se desenvolvendo no ocidente a partir das influências do liberalismo e do socialismo.

Entre estes modelos surgiram concepções que defendiam uma participação restrita da população no regime democrático, com participação somente no processo eleitoral e concepções que se colocaram contrárias à forma hegemônica, pois concebem a democracia como uma maneira pela qual a convivência humana deveria ser aperfeiçoada, instituindo-se novas determinações, novas normas e novas leis, conforme propõe Weber ${ }^{3}$ e Schumpeter ${ }^{4}$, Carole Pateman ${ }^{5}$ e Santos ${ }^{6}$.

Assim, durante o século $X X$, o debate sobre a democracia girou em torno de concepções que defendiam a restrição do papel da mobilização coletiva na formação de governo, supervalorizando o papel da representatividade, conforme assevera David Held "[...] denominada teoria democrática elitista (Held, s/d), que concebe a democracia como um procedimento de aquisição do poder através da competição, eleitoral entre políticos profissionais"" e concepções que defendiam um maior envolvimento dos indivíduos, não havendo uma restrição à participação.

Desta maneira, a práxis democrática foi sendo construída com base no pensamento ideológico que predominava em cada período. No século XIX, segundo Bobbio ${ }^{8}$, o debate sobre o tipo de democracia foi desenvolvido através de fortes embates entre as doutrinas políticas liberais e socialistas. Estas doutrinas buscaram responder a maneira como os países deveriam se organizar politicamente, seja através de um modelo restritivo ou participativo, nos poderes constitutivos das nações.

Nesta perspectiva, a concepção liberal sobre a prática democrática recebeu forte influência do pensamento de Benjamim Constant, expresso em "Da liberdade dos antigos comparada à dos mo-

3 WEBER, Max. Economy and society. University of California Press. 1978

4 SCHUMPETER, Joseph. Capitalismo, socialismo e democracia. Rio de Janeiro: Editora Fundo de Cultura, 1961.

5 PATEMAN, Carole. Participação e Teoria Democrática. Rio de Janeiro: Paz e Terra, 1992.

6 SANTOS, Boaventura Sousa; AVRITZER, Leonardo. Introdução: para ampliar o cânone democrático. In: SANTOS, Boaventura Sousa. Democratizar a democracia: os caminhos da democracia participativa. Rio de Janeiro: Civilização Brasileira, 2002.

7 RIBEIRO, Leandro Molhano. Algumas considerações sobre a teoria poliárquica. Disponível em: htttp:/www. iuperj.br/fórum dos alunos, 1993, pág. 47.

8 BOBBIO, Norberto. $\bigcirc$ futuro da democracia: uma defesa das regras do jogo. Tradução de Marco Aurélio Nogueira. Rio de Janeiro: Paz e Terra, 1986. 
dernos" ( I | |9), levando-a a ganhar adeptos tanto nos Estados Unidos como nos demais países que no século XX abraçaram a democracia liberal, conforme explicita Zakaria:

um sistema político caracterizado não só eleições livres e justas, mas também pelo Estado de direito, separação dos poderes e a proteção das liberdades fundamentais de expressão, reunião, religião e propriedade. ${ }^{9}$

Para Jürgen Habermas $^{10}$ ), a concepção liberal de democracia se ajusta na seguinte condição: "Na perspectiva liberal, o processo democrático se realiza exclusivamente na forma de compromissos de interesses", de uma elite que se beneficiava com o controle do processo político. Desta maneira, ao assumir uma forma concreta, a democracia liberal denominada também de democracia representativa, se caracteriza pela entrega do poder a um pequeno número de indivíduos que são escolhidos por meio de eleições.

Estes indivíduos, ao assumirem o poder, são responsáveis por criar e executar leis comuns a todos os cidadãos, estabelecendo seus direitos e deveres, portanto:

"A participação é também redefinida como manifestação daquela liberdade particular que indo além do direito de exprimir a própria opinião, de reunir-se ou de associar-se para influir na política do país, compreende ainda o direito de eleger representantes para o parlamento e de ser eleito."।

Nesta perspectiva, as teorias democráticas liberais do século XIX se caracterizavam por defender uma forma de governo majoritária, na qual, a busca pelo bem comum alicerçava a elaboração deste novo modelo que se espalhava pelo mundo.

Esta teoria democrática buscou então responder como seria possível desenvolver uma organização democrática em locais em que não existiam bases para sua implantação, além de questionar as formas de organização administrativa do Estado moderno e do poder que permeava tal estrutura, que incidia sobre os indivíduos. Combatendo a visão conservadora imposta no antigo regime, no entanto, a teoria liberal não conseguiu superar o elitismo político que outrora fez críticas.

Em contraposição ao modelo hegemônico, a concepção de democracia desenvolvida pelo socialismo defendia o sufrágio universal, sem restrições, como início das modificações necessárias que deveria passar a sociedade. Havia a defesa de uma democracia direta com maior participação popular e controle do poder sobre os diversos órgãos constitutivos da sociedade:

9 ZAKARIA, F. The Future of Freedom: Illiberal Democracy at Home and Abroad, W.W. Norton, 2003, págs. I5-I6.

I0 HABERMAS. Jurgen. Cap. VII Política Deliberativa: Um Conceito Procedimental de Democracia. In: Direito e Democracia: entre facticidade e validade. Rio de Janeiro: Tempo Brasileiro, 1997, pág. 19.

I I BOBBIO, Norberto. Dicionário de política. Trad. Carmen C. Varriale et al: Brasília: ed. Universidade de Brasília, 12 ed., 2004 , pág. 234. 
"Essas transformações são fundamentalmente duas: de um lado, a universalização do direito de voto e a implantação do sistema eleitoral proporcional e, do outro, o surgimento dos partidos de massa como instrumentos de mobilização, de canalização e de disputa do processo eleitoral. Ao mesmo tempo em que essas transformações ocorriam no campo político, na área social a crescente mobilização do proletariado urbano gerou também significativas mudanças políticas decorrentes da organização e do desenvolvimento do movimento sindical."'12

O século $X X$ teve seu início marcado por diversas influências ideológicas e doutrinais que durante o século anterior haviam modificado a forma de pensar e agir da sociedade europeia, que foi transferida para América Latina pelo processo de colonialidade do ser, do saber e do poder.

Vislumbrando as diversas teorias democráticas que foram desenvolvidas ao longo do século XX e buscando considerar os aspectos mais diversos da realidade em que os regimes democráticos estavam se inserindo, se torna perceptível que "A polissemia do conceito democracia vincula-se às interpretações teórico-ideológicas que atribuem sentido às experiências de socialização, bem como a projetos de sociedade".'3

Entre estas teorias destacamos a "Democracia Participativa" que tem em Carole Pateman ${ }^{14}$ um dos principais expoentes, defendendo que a democracia teria se afastado dos seus pressupostos básicos:

[...] a teoria democrática não está mais centrada na participação do povo, na participação do homem comum, nem se considera mais que a principal virtude de um sistema político democrático; reside no desenvolvimento das qualidades relevantes e necessárias, do ponto de vista político, no indivíduo comum; na teoria democrática contemporânea, o que importa é a participação da elite minoritária [...]. ${ }^{15}$

Por isso, se verifica que o modelo liberal se tornou hegemônico em diversos países do mundo no século $X X$, conduziram ao afastamento dos indivíduos comuns do processo decisório, tornando-a a práxis democrática uma forma de justificar a dominação política das elites liberais.

Em contraposição a democracia liberal, denunciada por Pateman, a perspectiva da participação popular, é vista como uma forma efetiva de fazer com que todos os indivíduos participem do processo de deliberação, não ficando restrito ao poder de votar. Esta via começou a ganhar força em todo mundo, pois visava ultrapassar a visão reducionista que a democracia representativa havia desenvolvido. Por isso, Pateman explica:

12 LeITE DE ALBUQUerQUe JúNIOR, Bento Costa Lima; MIRANDA, Márcio Mota. Democracia, Liberalismo e Socialismo. 2002, pág. 9.

13 RIBEIRO, Adelia Maria Miglievich; COUTINHO, George Gomes. Modelos de democracia na era das transições. civitas, Porto Alegre, v. 6 n. I, p.13-38, janeiro-junho 2006, pág. 13.

14 PATEMAN, Carole. Participação e Teoria Democrática. Rio de Janeiro: Paz e Terra, 1992.

15 Pateman, 1992 apud PERES, Paulo; FAUSTO, Priscila. Democracia Direta e Cidadania: Um Estudo de Caso sobre o Orçamento Participativo em Guarulhos. In: Congresso Luso-Afro-Brasileiro de Ciências Sociais. Sociedades Desiguais e Paradigmas em Confronto, 2009, Braga. Anais.... Braga, 2009, pág. 4. . 


\begin{abstract}
"A teoria democrática participativa é construída em torno da afirmação central de que os indivíduos e suas instituições não podem ser considerados isoladamente. A existência de instituições representativas a nível nacional não basta para a democracia, pois o máximo de participação de todas as pessoas, a socialização ou o treinamento social, precisa ocorrer em outras esferas, de modo que as atitudes e qualidades psicológicas necessárias possam se desenvolver. Esse desenvolvimento ocorre por meio do próprio processo de participação. A principal função da teoria da democracia participativa é, portanto, educativa; educativa no mais amplo sentido da palavra, tanto no aspecto psicológico como no que se refere à aquisição de habilidades e de prática de procedimentos democráticos. Por isso, não há nenhum problema especial quanto à estabilidade de um sistema participativo; ele se auto-sustenta por meio do seu impacto educativo. A participação promove e desenvolve as próprias qualidades que lhe são necessárias; quanto mais os indivíduos participam, melhor capacitados eles se tornam para fazê-lo." 16
\end{abstract}

A concepção liberal da democracia na segunda metade do século $X X$ começou a aparecer nos países que viveram sob regimes autoritários ou mesmo governos democráticos que cultivaram fortes desigualdades sociais e políticas como Portugal, Brasil, África do Sul, entre outros. Este processo de democratização e redemocratização possibilitou que houvesse uma abertura por parte dos governos para participação popular nos acontecimentos que atingem diretamente a sociedade, ainda que de forma bastante restrita, a exemplo do que ocorreu na África do Sul na luta pelo fim do apartheid, com o movimento cívico e o movimento sindical. No caso do Brasil o processo de redemocratização impulsionado pelos movimentos sociais, corroboraram para que houvesse abertura a participação, conforme ressalta Avritzer: "[...] Durante o processo brasileiro de democratização e de constituição de atores comunitários surgiu de modo semelhante à ideia do "direito a ter direitos"17, consolidando uma perspectiva de avanço no processo de democratização do espaço público.

\title{
I Atalhos para Democracia Participativa
}

Ao olhar as perspectivas políticas e suas ideias, se verifica que há democracias e democracias, analisá-las na atualidade nos leva a refletir sobre os diversos temas que envolvem o Estado e a participação da sociedade civil na organização de um espaço público que questione a democracia representativa como única forma de participação do povo, que se reduz a eleitor, que não precisa agir como agente político, pois delega a quem foi eleito a função de representá-lo na gestão pública: "[...] O homem e a mulher só são políticos no momento da escolha do voto. Essa é a única concessão da Democracia Representativa.

16 Idem.

17 AVRITZER, Leonardo. O Orçamento Participativo: As experiências de Porto Alegre e Belo Horizonte. In: DAGNINO, Evelina (Org.). Sociedade civil e espaços públicos no Brasil. São Paulo: Paz e Terra, 2002, pág. 56. 
Elegem e vão para casa, já desnudados de seu ser político"|8, eis uma perspectiva vigente no imaginário eleitoral do cidadão brasileiro, guardadas as exceções.

É na década de 1990 que o Brasil inicia o processo de implementação de direitos no campo social, econômico e político, por consequência da promulgação da Constituição de 1988, denominada "Constituição Cidadã".

A Carta Magna possibilitou a todos os cidadãos direito ao trabalho, salários dignos, a educação, a previdência social, a licença materna e paterna, aos indígenas de possuir a terra, entre outros. E no campo político destaca-se o maior poder de interferência da sociedade no regime democrático, com a utilização do sufrágio universal, o plebiscito, o referendo e a iniciativa popular. Além da criação de diversos mecanismos de participação da sociedade civil (Conselhos e Orçamento Participativo), assim: "A nova Constituição descentralizou poderes e estipulou importantes benefícios sociais similares às democracias mais avançada"|', se tornando uma referência para história do país.

Neste período, verificamos que as instituições próprias da democracia representativa, de forma específica o Poder Legislativo, representado no Brasil pelo Congresso Nacional, pelas Assembleias Legislativas e Câmaras Municipais, passaram a não dar respostas aos anseios da sociedade, é chamada crise de representação. Desta maneira, nos diversos municípios brasileiros foram surgindo experiências de Democracia Participativa com vistas a complementar o modelo de democracia liberal vigente. Assim, os cidadãos passaram a intervir diretamente na gestão pública, com a descentralização do poder em nível local, corroborando com o que afirmou Benevides "Logo, é função desses sagrados objetivos constitucionais que o povo deve participar - decidindo, cobrando e fiscalizando"20. Ou seja, a participação da sociedade civil, não mais se restringe apenas ao voto, vai além deste ato.

Lançando um olhar para administração pública brasileira, se verifica que é marcada pela constante busca pela organização, planejamento e execução de ações desenvolvidas pelo Estado através das organizações públicas, que limitam a democratização do espaço público. Entende-se que "Organizações Públicas: atuam nos níveis - Federal, Estadual e Municipal, e entre elas temos as que se configuram em Administração Direta e Administração Indireta." ${ }^{2}$. Neste sentido, se faz necessário o estabelecimento de normas e procedimentos que culminem com a realização do objetivo definido pelo Estado, que definirá o desenvolvimento democrático das organizações.

I8 SIGNORELLI, Carlos. Aprofundar a democracia: para um novo Estado. In: LESBAUPIN, Ivo; PINHEIRO, José Ernanne. (org). Democracia, igreja e cidadania: desafios atuais. São Paulo: Paulinas, 20 I0, pág. 45.

19 ZAVERUCHA, Jorge. FHC,forças armadas e política: entre o autoritarismo e a democracia (1999-2002). Rio de Janeiro: Record, 2005, pág. 59.

20 BENEVIDES, Maria Victoria. Nós, o povo: reformas políticas para radicalizar a democracia. In: BENEVIDES, Maria Victoria; VANNUCHI, Paulo; KERCHE, Fábio (Orgs). Reforma política e cidadania. São Paulo: Ed. Fundação Perseu Abramo \& Instituto Cidadania, 2005, pág. 88.

21 TRIGUEIRO, Francisco Mirialdo Chaves. Teorias da Administração. Florianópolis: Departamento de Ciências da Administração/ UFSC; Brasília: CAPES: UAB, 2009, pág. 19. 
Todavia, apesar das dificuldades do processo de implantação da democracia participativa em nosso país há um forte expoente com o desenvolvimento de experiências de Orçamentos Participativos, espalhados por diversos municípios do país, que começaram a questionar e solicitar a democratização do espaço público e suas organizações.

Isso é verificado pela forma como se deu o engajamento popular através da implantação do Orçamento Participativo que se caracteriza pela participação aberta de todos os cidadãos sem distinção alguma, combinando a democracia direta e representativa em relação à forma de como serão distribuídos os recursos para o investimento nas demandas elencadas pela sociedade local, assim com o modelo participativo: "No caso do Brasil, durante o processo de democratização os movimentos comunitários reivindicaram em diversas regiões do país, em particular na cidade de Porto Alegre, o direito de participar nas decisões em nível local'"22), impulsionando que em outros locais se desenvolva instrumentos parecidos, como no caso das cidades de Campina Grande e João Pessoa, na Paraíba. Em outros estados da região Nordeste (Bahia, Pernambuco e Ceará) também se desenvolveram instrumentos que proporcionaram a participação social.

modelo de participação popular depende do poder de mobilização que os cidadãos desempenham ao pressionar o governo para atuarem de forma mais transparente e eficiente, sendo uma prática perseguida pelos movimentos sociais, que propõe uma experiência em que os cidadãos tenham um maior controle sobre as ações governamentais, quebrando o afastamento que ocorre com o término do processo eleitoral.

É interessante perceber que o Orçamento Participativo emerge no seio de uma instituição partidária, que foi o Partido dos Trabalhadores de Porto Alegre, impulsionado pela pressão dos movimentos sociais. Algo que demonstra a mudança de hábito na sociedade, que passa a ser convocada não só para fornecer apoio eleitoral, mas dar uma contribuição no processo de distribuição orçamentária das cidades, recebendo amplo apoio dos movimentos sociais que lutam por uma maior participação dos cidadãos, assim: "Os movimentos sociais estariam em movimento pela ampliação do político, pela transformação de práticas dominantes, pelo aumento da cidadania e pela inserção na política de atores sociais excluídos"'23, é a disseminação participação popular na administração pública.

No Estado da Paraíba alguns municípios implantaram os orçamentos participativos municipais, como Campina Grande e João Pessoa, se apoiando no modelo da cidade de Porto Alegre - RS e recebendo apoio dos movimentos sociais destas cidades. No entanto, ao vislumbrar o caso da Paraíba este difere da atuação nos municípios, pois o instrumento do Orçamento Democrático atua no nível estadual com abrangência em todo território estadual.

22 SANTOS, Boaventura Sousa; AVRITZER, Leonardo. Introdução: para ampliar o cânone democrático. In: SANTOS, Boaventura Sousa. Democratizar a democracia: os caminhos da democracia participativa. Rio de Janeiro: Civilização Brasileira, 2002, pág. 58.

23 SANTOS, Boaventura Sousa; AVRITZER, Leonardo. Introdução: para ampliar o cânone democrático. In: SANTOS, Boaventura Sousa. Democratizar a democracia: os caminhos da democracia participativa. Rio de Janeiro: Civilização Brasileira, 2002, pág. 53. 
Desta forma, ao analisar o processo de implementação da Democracia Participativa no Estado da Paraíba, se averígua que foi desenvolvida uma prática administrativa por meio do Orçamento Democrático Estadual, que estabeleceu uma gestão estratégica, que tem por princípio a participação dos cidadãos no sistema político representativo, através dos Conselhos de Participação, atingindo todos os municípios que formam o Estado da Paraíba.

Essa atuação dos cidadãos e cidadãs visa preencher uma lacuna existente no processo de fiscalização das ações do Estado, que ocorre de forma deteriorada, desarticulada, corrompida pelos gestores públicos. Conforme ressalta Gomes "O cidadão deve exercer o controle social sobre os mandatos legislativos e executivos por meio da participação nos orçamentos públicos e no funcionamento da justiça"24. Desta maneira, há tendência de inibir o abuso de poder por parte dos gestores públicos. Ocorrendo assim, o desenvolvimento de uma gestão pública estadual, que realize uma abertura, uma descentralização administrativa, conforme verificamos:

"[...] Esse novo modelo vem do que pode ser chamado de reformas de segunda geração, por incluir não apenas medidas de contenção fiscal, mas sobretudo, o fortalecimento do gerenciamento público, de instituições de controle e imputação de resultados e estruturas mais flexíveis em que o cidadão pode se perceber e ter voz, como usuário de serviços públicos e contribuinte." 25

Nesta perspectiva, a emergência do Orçamento participativo ${ }^{26}$, que é um dos instrumentos adotados no Estado Brasileiro por meio dos seus municípios e estados, que tem como objetivo aproximar os cidadãos do processo decisório dos gastos que este ente da federação irá dispor para melhorar as condições dos que habitam o território estadual. Por isso, Lesbaupin (2010, p. 31 ) expressa: "Os novos governos democráticos estão introduzindo novas instituições políticas, novas leis - através de reformas constitucionais - que permitem uma participação mais direta dos cidadãos, [...]". Desta maneira, o Estado da Paraíba adotou como estratégia de inovação da gestão pública o Orçamento Democrático Estadual, com base nas seguintes medidas administrativas:

"MEDIDA PROVISÓRIA N" 160, DE OI DE JANEIRO DE 2011. O GOVERNADOR DO ESTADO DA PARAÍBA, no uso da atribuição que the confere o art. $63, \S 3^{\circ}$, da Constituição do Estado, adota a seguinte Medida Provisória, com força de Lei: IX

24 GOMES, Lucrecia Anchieschi; SANTOS, Luciano Pereira dos. Policidadania: política e cidadania. 2. ed. São Paulo: Paulinas, 2009, pág. 26.

25 COSTIN, Cláudia. Administração pública. Rio de Janeiro: Elsevier, 20 I0, pág. 33.

26 orçamento participativo é um importante instrumento de complementação da democracia representativa, pois permite que o cidadão debata e defina os destinos de uma cidade. Nele, a população decide as prioridades de investimentos em obras e serviços a serem realizados a cada ano, com os recursos do orçamento da prefeitura. Além disso, ele estimula o exercício da cidadania, o compromisso da população com o bem público e a corresponsabilização entre governo e sociedade sobre a gestão da cidade. E na Paraíba, adotou-se a nomenclatura de Orçamento Democrático Estadual. (Disponível em: < http://www.planejamento. gov.br/servicos/faq/orcamento-da-uniao/elaboracao-e-execucao-do-orcamento/o-que-e-orcamento-participativo>, Acesso em $04 / 11 / 2016)$. 
- Subsecretaria Executiva do Orçamento Democrático. LEI No 9.332, DE 25 DE JANEIRO DE 20 I : Faço saber que o Governador do Estado da Paraíba adotou a Medida Provisória n 160 de 0 I de janeiro de 20 I I; que a Assembleia Legislativa aprovou, e eu, Ricardo Marcelo, Presidente da Mesa da Assembleia Legislativa, para os efeitos do disposto na Emenda Constitucional n 32 de 2001 da Constituição Federal e do Art. 63, § $3^{\circ}$ da Constituição do Estado da Paraíba c/c a Resolução n 982/2005 da Assembleia Legislativa, PROMULGO, a seguinte Lei: Art. $2^{\circ}$ Passam a denominar-se: IX - Subsecretaria Executiva do Orçamento Democrático, a Subsecretaria Executiva da Educação."'27.

Deste modo, a articulação da sociedade civil por meio do Orçamento Democrático demonstra que uma nova maneira de participação é desenvolvida, seguindo o que acontece em diversos países democráticos, que em tese dão abertura para que a participação ocorra. Ao vislumbrar o espaço de articulação entre Estado e sociedade civil, se verifica uma redefinição da participação como um exercício da cidadania ativa.

\section{Democratizando o espaço público}

Ao refletir sobre a estrutura do Estado na atualidade, Jacobi ${ }^{28}$ (2000) defende que a centralização administrativa é um atraso, pois conduz a ineficiência no desenvolvimento das políticas setoriais e dos serviços públicos, além disso, demonstra o retrocesso democrático, necessitando desta maneira de uma redefinição quanto à relação entre Estado e sociedade. Conforme salienta: "A questão da descentralização é hoje uma das principais precondições para formular uma efetiva democratização do Estado"29, o que dá impulso para um modelo participativo seja realizado em todos os níveis da administração pública.

Observando a estrutura administrativa do Estado da Paraíba, se percebe que possui uma divisão regional, que busca estabelecer e demarcar uma organização administrativa e de atuação deste ente em seu território pelo estabelecimento destas regiões, assim:

"No nível intermediário, temos os Estados da Federação, como Mato Grosso,

Paraíba e Santa Catarina. São organizações responsáveis pela administração dos recursos públicos regionais para atendimento das necessidades da sociedade." ${ }^{30}$.

A divisão geo-administrativa ${ }^{31}$ do Estado da Paraíba, criada pelos Decretos: 12.984 de 17/02/1989, |4. $17 \mid$ de 19/| |/199| e 30.531 de 14/08/2009 define quais as regiões administrativas do Estado.

27 Diário oficial do Estado da Paraíba . 01 de Janeiro de 20। I. Disponível em: http://paraiba.pb.gov.br/diario-oficial

28 JACOBI, Pedro Roberto. Políticas sociais e ampliação da cidadania. Rio de Janeiro: ed. FGV, 2000.

29 Íbid., pág. 35.

30 TRIGUEIRO, Francisco Mirialdo Chaves. Teorias da Administração. Florianópolis: Departamento de Ciências da Administração/ UFSC; Brasília: CAPES: UAB, 2009, pág. 20.

3I Ver anexo. 
Demarcando assim um planejamento estratégico para aplicação dos recursos públicos.

Aproveitando esta divisão, o Governo atual instituiu o Orçamento Democrático Estadual, por meio da Medida Provisória, citada acima, foi criada a Subsecretaria Executiva, que teria a responsabilidade de colocar em prática em ação estratégica de administração pública baseada na participação dos indivíduos, assim verificamos que:

"A gestão estratégica necessita seguir uma orientação voltada às demandas e expectativas de comunidade, do contexto social mais amplo, encontrado no Planejamento Estratégico um instrumento de suma importância para atingir e/ou alcançar as expectativas dos serviços cidadão/cliente da comunidade e do contexto social mais amplo.". 32

Ao assumir a democratização da gestão pública com participação popular verifica-se que o Estado é colocado como principal agente de fornecimento de políticas sociais, que é influenciado pelos grupos de interesse e não se restringindo apenas aos seus interesses globais. Para Jacobi, o problema a ser enfrentado é articular a democracia política com a participação social, conforme expressa:

"[...] Nesse sentido, a participação social se apresenta como importante instrumento de fortalecimento da sociedade civil, notadamente dos setores mais excluídos; na medida em que a superação das carências acumuladas depende basicamente da interação de agentes públicos e privados no contexto de arranjos sócio-institucionais estratégicos".33

Desta maneira, vislumbramos que a participação tem sua ligação direta com o processo de democratização do espaço público, a partir da criação e fortalecimento dos espaços de negociação, descentralização do poder, com forte presença de indivíduos autônomos em relação aos governos. Além disso, se deve perceber que a participação ocorre a partir da articulação do Estado com os sujeitos sociais.

Ao visualizar o Orçamento Democrático Estadual, entendemos que é um instrumento político e estratégico para gerir o Estado da Paraíba, pois carrega em si uma maior aproximação entre cidadãos e cidadãs do processo decisório. Sua formatação compreende meios formais ou informais pelos quais são discutidos o desenvolvimento de políticas públicas, que fazem com que existam uma interação entre sociedade civil e Estado. Assim: "[...] ○ OP é a população tomando em suas mãos o próprio processo administrativo, já que a proposta e a execução orçamentárias são o cerne de toda administração pública" 34 , é a busca por complementar a democracia representativa com a democracia participativa.

32 KANAANE, Roberto; FIEL Filho, Alécio; FERREIRA, Maria das Graças. Gestão pública: planejamento, processos, sistemas de pessoas. São Paulo: Atlas, 2010, pág. 59.

33 JACOBI, Pedro Roberto. Políticas sociais e ampliação da cidadania. Rio de Janeiro: ed. FGV, 2000. Íbid., pág. 27.

34 SIGNORELLI, Carlos. Aprofundar a democracia: para um novo Estado. In: LESBAUPIN, Ivo; PINHEIRO, José Ernanne. (org). Democracia, igreja e cidadania: desafios atuais. São Paulo: Paulinas, 20 I0, pág. 69. 
Orçamento Democrático propõe que seja criada uma nova forma de intervenção cidadã nas questões que afetam diretamente a sociedade civil, que passam a expor sua vontade nas decisões que são tomadas pelo Poder Executivo e consolidadas pelo Poder Legislativo. Tal acontecimento acaba por reduzir as distâncias que existem entre os cidadãos e os poderes constituídos, que normalmente só é reduzida durante o processo de escolhas dos membros do legislativo e do executivo no processo eleitoral:

"Essa intervenção política configura-se como a criação de um novo direito político, na linha de um T. H. Marshall, enriquecendo o arsenal de instâncias em que as classes e grupos sociais intervêm ativamente no governo. Tal participação não se daria apenas na renovação dos mandatos, mas cotidianamente e sem anular as instâncias. A intervenção se dá, precisamente, na discussão do orçamento, que é, no Estado moderno, a peça-chave da política e da administração." 35

Neste sentido, visualizar a Gestão Estratégica desenvolvida pelo Governo da Paraíba, através da Secretaria de Estado de Planejamento e Gestão, por meio do instrumento participativo que é o Orçamento Democrático, se verifica que este possui um processo organizacional que conduz a administração pública a trazer para o diálogo a sociedade civil, durante o processo de elaboração do orçamento público estadual, assim:

"[...] a transformação da administração requer mudanças estruturais, das regras e dos processos, e medidas efetivas objetivando a criação que visa contemplar as posições das partes envolvidas, ou seja, possibilitando ao cidadão cliente influenciar no direcionamento das políticas públicas em prol das cidades na qual se insere." ${ }^{36}$.

Ao observar o Orçamento Democrático Estadual, se constata uma característica marcante, que é a convocação dos cidadãos a participar das decisões do governo estadual, expressando sua opinião acerca de como a gestão pública pode melhor investir os recursos financeiros estaduais. Ou seja, a missão deste instrumento é conduzir o cidadão ao diálogo com o poder Executivo Estadual.

Neste contexto, Avritzer ${ }^{37}$, define que o Orçamento Democrático é uma maneira de reequilibrar e articular a democracia representativa e a democracia participativa. Por isso, devem ser observados os seguintes critérios: cessão de soberania por quem detém o poder representativo local; reintrodução de elementos de participação local (assembleias regionais, conselhos), combinando-se aí métodos de democracia participativa, auto-regulação soberana a partir da definição de regras e procedimen-

35 OLIVEIRA, Francisco; PAOLI, Maria Célia; e REZEK, Cibele Saliba. Orçamento participativo: uma invenção política. In: BENEVIDES, Maria Victoria; VANNUCHI, Paulo; KERCHE, Fábio (Orgs.). Reforma Política e Cidadania. São Paulo: Instituto Cidadania e ed. Fundação Perseu Abramo, 2005, pág.224.

36 KANAANE, Roberto; FIEL Filho, Alécio; FERREIRA, Maria das Graças. Gestão pública: planejamento, processos, sistemas de pessoas. São Paulo: Atlas, 2010 , pág. 38.

37 2005, pág. 14 apud TIENE, 2010 
tos pelos participantes do OP e a reversão das prioridades de recursos públicos locais em prol das populações em situação de vulnerabilidade.

Desta maneira, ao vislumbrar os princípios que norteiam este instrumento da gestão estratégica, se verifica que uma nova maneira de relacionamento entre o Governo do Estado e a sociedade civil é gestada por meio do Orçamento Democrático,

"I - Democratização - ampliação do espaço de exercício da cidadania e governança democrática; 2 - a Participação - promoção do empoderamento, do controle e da corresponsabilidade social; 3 - a Regionalização - os municípios passam articular os interesses regionalmente e não mais de modo particular a cada cidade sem, contudo perder suas características; 4 - a Intersetorialidade - como instrumento de ação integrada de diferentes atores e institucionais e não governamentais, através de uma rude articulação regional e estadual; 5 - a Economicidade - realizar mais políticas públicas, obras e serviços, com menos recursos; 6 - a Descentralização - promover a articulação institucional nas regiões geo-administrativas; 7 - a Redistribuição - redistribuir as políticas públicas, investimentos, obras e serviços concentrados em alguns pontos das regiões do Estado; e 8 - o Desenvolvimento Integrado Sustentável - priorizar as características culturais e sócio-ambientais das regiões e suas potencialidades." ${ }^{38}$.

Com a institucionalização do orçamento democrático foi possível que os cidadãos e cidadãs do Estado da Paraíba tivesse a condição de interferir no processo decisório, sem ter mediadores, mas atuando de forma direta nas audiências públicas. Tal fato ocasionou no Brasil e na Paraíba o despontar de um novo modelo de participação popular na gestão administrativa, colaborando para a transformação de sociedade através das ações dos indivíduos que, de forma consciente, buscam modificar a realidade.

Para que fosse possível a implantação e funcionamento do Orçamento Democrático, foi aproveitada a Divisão geo-administrativa do Estado da Paraíba, que criou para o instrumento as regiões orçamentárias (ver anexo I), visando definir uma redistribuição de recursos de forma regionalizada.

Ao analisar a proposta da divisão do Estado da Paraíba em regiões orçamentárias com Orçamento Democrático Estadual, verificamos que o Governo Estadual buscou atuar no sentido de configurar um modelo de administração pública que possibilitasse a transferência de poder aos cidadãos, papéis de agentes destes instrumentos, com função de elencar as necessidades das comunidades representadas, fiscalizar aplicação do dinheiro público e propor ações que visem a melhoria da qualidade de vida da população que habita em cada região geo-adminitrativa do Estado da Paraíba.

No processo de democratização do Estado surgiram novas práticas de gestão e governança na Paraíba, tomando, segundo Leal (2003) duas vertentes principais: uma se constituiu a partir das normas

38 PARAÍBA. Guia do Orçamento Democrático Estadual. Princípios, funções e etapas. João Pessoa, 20 I I, pág. I. 
institucionais estabelecidas pela Constituição de 1988, no qual se configuraram espaços organizacionais e institucionais dentro das administrações, tais como, Conselhos, Planos Diretores, Leis Orgânicas, Orçamentos Participativos, além de outras práticas de descentralização e participação popular. A segunda vertente resulta da necessidade de estabelecer novas formas de governança às cidades, que passam a ser protagonistas do empreendimento urbano ou do chamado empreendedorismo municipal, que torna o município responsável pelo desenvolvimento local através de projetos estratégicos que passaram a ser um instrumento para dar respostas às crises e para atender às aspirações de uma inserção econômica das cidades no contexto global. Fato que é endossado pela percepção de Borja "[...] os processos sociais econômicos, culturais e populacionais tendem a globalizar-se, mas seus efeitos concentram-se nas aglomerações urbanas e requerem atuações políticas integradas." 39 , é o processo reestruturação das gestões.

Com o estabelecimento do Orçamento Democrático, instrumento de planejamento estatal baseado na participação da sociedade civil, dá subsídios para que os indivíduos acompanhem as ações desenvolvidas pelo Poder Executivo no que diz respeito ao orçamento estadual, tornando mais transparente e descentralizador o emprego do recurso público, fugindo da forma tradicional de elaboração das leis orçamentárias (Lei de Diretrizes Orçamentárias; Lei do Plano Plurianual e Lei do Orçamento Anual), que excluía a participação da sociedade civil neste processo:

"[...] Nos entes federativos brasileiros, competem aos Ministérios e às respectivas Secretarias de Planejamento a previsão, a dotação (divisão dos recursos entre os órgãos e suas finalidades) e o controle da execução orçamentária." ${ }^{40}$.

Neste sentido, para Avritzer, o orçamento democrático é um acontecimento que permite a transferência de mediação dos políticos para a população sobre a distribuição de bens materiais através da constituição de esferas públicas: assembleias, listas de acesso anterior a bens matérias, critérios de carência, dando margem para que não haja particularismos, mas que o Orçamento Democrático tenha seu objetivo alcançado. Por isso, afirma que: "São as novas práticas capazes de radicalizar o exercício da democracia que tornam esta última legítima aos olhos daqueles de cuja autorização e a democracia irá sempre depender, dos cidadãos"'4!, que passam a participar da gestão pública de forma ativa e consciente.

\section{Considerações finais}

É notório que o processo de institucionalização da participação só irá se consolidar com a viva participação dos movimentos sociais e a partir daí seja motivado à legitimidade da democratização da gestão pública.

39 apud LEAL, Suely. Fetiche da Participação popular: novas práticas de planejamento, gestão e governança democrática no Recife - Brasil. Recife: Ed. do Autor, 2003, pág. 59.

40 KANAANE, Roberto; FIEL Filho, Alécio; FERREIRA, Maria das Graças. Gestão pública: planejamento, processos, sistemas de pessoas. São Paulo: Atlas, 2010 , pág. 38.

$4 I$ AVRITZER, Leonardo. O Orçamento Participativo: As experiências de Porto Alegre e Belo Horizonte. In: DAGNINO, Evelina (Org.). Sociedade civil e espaços públicos no Brasil. São Paulo: Paz e Terra, 2002, pág. 43. 
Este processo de descentralização, no entanto, não é fácil de realizar, mas só existe devido à capacidade que a sociedade civil tem de dialogar e buscar confirmar sua posição de defesa da sociedade contra a quase total dominação do Estado, sobretudo no que diz respeito às questões orçamentárias.

Por ser uma nova estrutura na administração pública, o Orçamento Democrático Estadual possui um manual que explica a organização, finalidade, as normas e regras de seu funcionamento. Sua elaboração foi de responsabilidade do poder Executivo, através da Subsecretaria do Orçamento Democrático, que compõe a estrutura administrativa do governo e subordinado a Secretária de Estado de Planejamento e Gestão - SEPLAG. Seguindo desta maneira, o que afirmou Benevides:

"[...] Uma estrutura e um processo de participação baseados em três princípios e em um conjunto de instituições que funciona como mecanismo ou canal que assegura a participação no processo decisório do governo municipal. Esses princípios são: I) participação aberta a todos os cidadãos sem nenhum status especial atribuído a qualquer organização, inclusive as comunitárias; 2) combinação da democracia direta e representativa, cuja dinâmica institucional concede aos próprios participantes a definição das regras internas; e 3) alocação dos recursos para investimentos baseada na combinação de critérios gerais e técnicos, ou seja, compatibilidade entre as decisões e as regras estabelecidas pelos participantes e as exigências técnicas e legais da ação governamental, respeitando também os limites financeiros." . 42

Nesta perspectiva, se vislumbrar que o Orçamento Democrático Estadual pode se tornar num importante instrumento de gestão estratégica, que aproxima os cidadãos para encarar o Estado de perto, por dentro, refletindo o contexto estadual que outrora ao estabelecimento deste instrumento não dispunha de outro meio para dialogar com os cidadãos de forma aberta e transparente, tanto por parte dos que estão a governar como atendendo os governados, apoiando-se na famosa afirmação de Aristóteles: "cidadão é aquele capaz de governar e ser governado", parece ser este um ideal perseguido na Paraíba.

Ao discorrer sobre o Orçamento Democrático Estadual se percebe que é um instrumento, não só de planejamento estratégico, mas um instrumento social, permeado por diversas vontades, por isto, se faz necessário compreender quais os limites das ações desenvolvidas pelos cidadãos que participam do instrumento. Desta maneira, segundo Cortella (2002) se deve perceber a participação popular como uma forma eficaz de conduzir os indivíduos para o diálogo e para elaboração da cidadania.

Compreende-se que com a utilização deste instrumento uma nova cultura política passa a ser elaborada, pois os cidadãos e cidadãs passam a ter uma atitude proativa em relação aos destinos do dinheiro público de seu estado, bem como percebemos qual a visão da administração pública estadual, que vê a participação popular um importante aliado na busca de uma gestão planejada e participativa.

42 BENEVIDES, Maria Victoria. Nós, o povo: reformas políticas para radicalizar a democracia. In: BENEVIDES, Maria Victoria; VANNUCHI, Paulo; KERCHE, Fábio (Orgs). Reforma política e cidadania. São Paulo: Ed. Fundação Perseu Abramo \& Instituto Cidadania, 2005, pág. 109. 
Assim, o Orçamento Democrático se consolida como um instrumento que busca modificar e ampliar a consciência política e participativa dos cidadãos, conforme afirma Teixeira [...] "À sociedade civil cabe, sim, zelar pela transparência das ações e responsabilização dos que as promovem, pois, autolimitada, não pretende substituir o Estado" 43 . Ao poder administrativo, legitimado politicamente, cabe tomar a decisão, conforme parâmetros consensualmente construídos, consolidando uma prática participativa que gere resultados aceitáveis na busca de uma qualidade de vida melhor da população do Estado da Paraíba que se caracteriza por inovar sua visão administrativa, abrindo aos cidadãos e cidadãs as portas da gestão pública estadual para a corresponsabilidade e transparência dos recursos públicos.

\section{Referências}

AVRITZER, Leonardo. O Orçamento Participativo: As experiências de Porto Alegre e Belo Horizonte. In: DAGNINO, Evelina (Org.). Sociedade civil e espaços públicos no Brasil. São Paulo: Paz e Terra, 2002. cap. 2.

BENEVIDES, Maria Victoria. Nós, o povo: reformas políticas para radicalizar a democracia. In: BENEVIDES, Maria Victoria; VANNUCHI, Paulo; KERCHE, Fábio (Orgs). Reforma política e cidadania. São Paulo: Ed. Fundação Perseu Abramo \& Instituto Cidadania, 2005, págs. I 20- 132.

BOBBIO, Norberto. O futuro da democracia: uma defesa das regras do jogo. Tradução de Marco Aurélio Nogueira. Rio de Janeiro: Paz e Terra, 1986.

12 ed., 2004.

CÂMARA DOS DEPUTADOS. Seminário Democracia e Soberania Popular. 05/0 I/200 I.

CORTELLA, Mário Sérgio. Democracia, Cidadania e Participação. Brasília: Coordenação de Publicações, 2002.

COSTIN, Cláudia. Administração pública. Rio de Janeiro: Elsevier, 2010.

DAGNINO, Evelina. (org.) Sociedade civil e espaços públicos no Brasil. São Paulo: Paz e Terra, 2002.

HABERMAS. Jurgen. Cap. VII Política Deliberativa: Um Conceito Procedimental de Democracia. In:

Direito e Democracia: entre facticidade e validade. Rio de Janeiro: Tempo Brasileiro, 1997, pág. 9-55.

GOMES, Lucrecia Anchieschi; SANTOS, Luciano Pereira dos. Policidadania: política e cidadania. 2. ed. São Paulo: Paulinas, 2009.

JACOBI, Pedro Roberto. Políticas sociais e ampliação da cidadania. Rio de Janeiro: ed. FGV, 2000.

43 TEIXEIRA, E. C. "O local e o global: limites e desafios da participação cidadã". São Paulo: Cortez; Recife: EQUIP; Salvador: UFBA, 2001 , pág. 196. 
KANAANE, Roberto; FIEL Filho, Alécio; FERREIRA, Maria das Graças. Gestão pública: planejamento, processos, sistemas de pessoas. São Paulo: Atlas, 2010.

LEAL, Suely. Fetiche da Participação popular: novas práticas de planejamento, gestão e governança democrática no Recife - Brasil. Recife: Ed. do Autor, 2003.

LEITE DE ALBUQUERQUE JÚNIOR, Bento Costa Lima; MIRANDA, Márcio Mota. Democracia, Liberalismo e Socialismo. 2002. Disponível em: <http://www.achegas.net/numero/cinco/bento_e_marcio.htm>. Acesso em: 17 dezembro 2009.

LESBAUPIN, Ivo; PINHEIRO, José Ernanne. (org). Democracia, Igreja e cidadania: desafios atuais. São Paulo: Paulinas, 2010.

OLIVEIRA, Francisco; PAOLI, Maria Célia; e REZEK, Cibele Saliba. Orçamento participativo: uma invenção política. In: BENEVIDES, Maria Victoria; VANNUCHI, Paulo; KERCHE, Fábio (Orgs.). Reforma Política e Cidadania. São Paulo: Instituto Cidadania e ed. Fundação Perseu Abramo, 2005, págs. I 34- 158.

PATEMAN, Carole. Participação e Teoria Democrática. Rio de Janeiro: Paz e Terra, 1992.

PARAÍBA. Guia do Orçamento Democrático Estadual. Princípios, funções e etapas. João Pessoa, 201 l.

PERES, Paulo; FAUSTO, Priscila. Democracia Direta e Cidadania: Um Estudo de Caso sobre o Orçamento Participativo em Guarulhos. In: Congresso Luso-Afro-Brasileiro de Ciências Sociais. Sociedades Desiguais e Paradigmas em Confronto, 2009, Braga. Anais... Braga, 2009, págs. I-22. Disponível em <works.bepress. com/pauloperes/3/ >. Acesso em: 15-07-2010

RIBEIRO, Adelia Maria Miglievich; COUTINHO, George Gomes. Modelos de democracia na era das transições. civitas, Porto Alegre, v. 6 n. I, p. I3-38, janeiro-junho 2006.

SANTOS, Boaventura Sousa; AVRITZER, Leonardo. Introdução: para ampliar o cânone democrático. In: SANTOS, Boaventura Sousa. Democratizar a democracia: os caminhos da democracia participativa. Rio de Janeiro: Civilização Brasileira, 2002, págs.39-78.

SIGNORELLI, Carlos. Aprofundar a democracia: para um novo Estado. In: LESBAUPIN, Ivo; PINHEIRO, José Ernanne. (org). Democracia, igreja e cidadania: desafios atuais. São Paulo: Paulinas, 20 I0. págs.4I-74.

SCHUMPETER, Joseph. Capitalismo, socialismo e democracia. Rio de Janeiro: Editora Fundo de Cultura, 1961.

TEIXEIRA, E. C. "O local e o global: limites e desafios da participação cidadã". São Paulo: Cortez; Recife: EQUIP; Salvador: UFBA, 2001.

TIENE, Izalene. Prática democrática e poder local: Orçamento Participativo. 2010.

LESBAUPIN, Ivo; PINHEIRO, José Ernanne. (org). Democracia, Igreja e Cidadania: desafios atuais. São Paulo: Paulinas, 2010, págs.87-99.

TRIGUEIRO, Francisco Mirialdo Chaves. Teorias da Administração. Florianópolis: Departamento de Ciências da Administração/ UFSC; Brasília: CAPES: UAB, 2009. 
WEBER, Max. Economy and society. University of California Press. 1978.

ZAKARIA, F. The Future of Freedom: Illiberal Democracy at Home and Abroad, W.W. Norton, 2003.

O Futuro da Liberdade: a Democracia Liberal nos Estados Unidos e no Mundo. Lisboa: ed. Gravida, 2004.

ZAVERUCHA, Jorge. FHC,forças armadas e política: entre o autoritarismo e a democracia (1999-2002). Rio de Janeiro: Record, 2005.

\section{ANEXO I}

\section{DIVISÃO GEOADMINISTRATIVA DO ESTADO DA PARAÍBA}

INSTRUMENTO DO ORÇAMENTO DEMOCRÁTICO

\section{$I^{a}$ REGIÃO GEOADMINISTRATIVA - Sede: JOÃO PESSOA}
01. Alhandra
08. Lucena
02. Bayeux
09. Mari
03. Caaporã
10. Pitimbu
04. Cabedelo
| l. Riachão do Poço
05. Conde
12. Santa Rita
06. Cruz do Espírito Santo
13. Sapé
07. João Pessoa
14. Sobrado

\section{$2^{\mathrm{a}}$ REGIÃO GEOADMINISTRATIVA - Sede: GUARABIRA}
01. Alagoinha
07. Cacimba de Dentro
02. Araçagi
08. Caiçara
03. Araruna
09. Campo de Santana
04. Bananeiras
10. Casserengue
05. Belém
II. Cuitegi
06. Borborema
12. Dona Inês 

13. Duas Estradas
19. Pirpirituba
14. Guarabira
20. Riachão
15. Logradouro
21. Serra da Raiz
16. Mulungu
22. Serraria
17. Pilões
23. Sertãozinho
18. Pilõezinhos
24. Solânea

\section{$3^{\text {a }}$ REGIÃO GEOADMINISTRATIVA - Sede: CAMPINA GRANDE}
01. Alagoa Grande
18. Fagundes
02. Alagoa Nova
19. Gado Bravo
03. Alcantil
20. Juazeirinho
04. Algodão de Jandaíra
21. Lagoa Seca
05. Arara
22. Livramento
06. Areia
23. Massaranduba
07. Areial
24. Matinhas
08. Aroeiras
25. Montadas
09. Assunção
26. Natuba
10. Barra de Santana
27. Olivedos
| ।. Barra de São Miguel
28. Pocinhos
12. Boa Vista
29. Puxinanã
13. Boqueirão
30. Queimadas
14. Cabaceiras
31. Remígio
15. Campina Grande
32. Riacho de Santo Antônio
16. Caturité
33. Santa Cecília
17. Esperança
34. São Domingos do Cariri 
35. São Sebastião de Lagoa de Roça

36. Soledade

37. Taperoá

$4^{a}$ REGIÃO GEOADMINISTRATIVA - Sede: CUITÉ
38. Tenório

39. Umbuzeiro
01. Baraúna
07. Nova Floresta
02. Barra de Santa Rosa
08. Nova Palmeira
03. Cubati
09. Pedra Lavrada
04. Cuité
10. Picuí
05. Damião
| |. Seridó
06. Frei Martinho
12. Sossêgo

\section{$5^{\text {a }}$ REGIÃO GEOADMINISTRATIVA - Sede: MONTEIRO}
01. Amparo
10. Prata
02. Camalaú
II. Santo André
03. Caraúbas
12. São João do Cariri
04. Congo
13. São João do Tigre
05. Coxixola
14. São José dos Cordeiros
06. Gurjão
15. São Sebastião do Umbuzeiro
07. Monteiro
16. Serra Branca
08. Ouro Velho
17. Sumé
09. Parari
18. Zabelê

\section{$6^{\mathrm{a}}$ REGIÃO GEOADMINISTRATIVA - Sede: PATOS}
01. Areia de Baraúnas
04. Catingueira
02. Cacimba de Areia
05. Desterro
03. Cacimbas
06. Emas 

07. Junco do Seridó
15. Santa Luzia
08. Mãe D’Água
16. Santa Terezinha
09. Malta
17. São José de Espinharas
10. Matureia
18. São José do Bonfim
II. Passagem
19. São José do Sabugi
12. Patos
20. São Mamede
13. Quixaba
21. Teixeira
14. Salgadinho
22. Várzea

\section{$7^{\text {a }}$ REGIÃO GEOADMINISTRATIVA - Sede: ITAPORANGA}
01. Aguiar
10. Nova Olinda
02. Boa Ventura
1।. Olho D'Água
03. Conceição
12. Pedra Branca
04. Coremas
13. Piancó
05. Curral Velho
14. Santa Inês
06. Diamante
15. Santana de Mangueira
07. Ibiara
16. Santana dos Garrotes
08. Igaracy
17. São José de Caiana
09. Itaporanga
18. Serra Grande

\section{$8^{a}$ REGIÃO GEOADMINISTRATIVA - Sede: CATOLÉ DO ROCHA}
0।. Belém do Brejo do Cruz
06. Jericó
02. Bom Sucesso
07. Mato Grosso
03. Brejo do Cruz
08. Riacho dos Cavalos
04. Brejo dos Santos
09. São Bento
05. Catolé do Rocha
10. São José do Brejo do Cruz 


\section{$9^{a}$ REGIÃO GEOADMINISTRATIVA - Sede: CAJAZEIRAS}

01. Bernardino Batista

02. Bom Jesus

03. Bonito de Santa Fé

04. Cachoeira dos Índios

05. Cajazeiras

06. Carrapateira

07. Monte Horebe 15. Uiraúna

08. Poço Dantas
09. Poço de José de Moura

10. Santa Helena

| I. Santarém

12. São João do Rio do Peixe

13. São José de Piranhas

14. Triunfo

15. Uiraúna

I0 $0^{\mathrm{a}}$ REGIÃO GEOADMINISTRATIVA - Sede: SOUSA
0l. Lastro
05. São Francisco
02. Marizópolis
06. São José da Lagoa Tapada
03. Nazarezinho
07. Sousa
04. Santa Cruz
08. Vieirópolis

I I ${ }^{\text {a }}$ REGIÃO GEOADMINISTRATIVA - Sede: PRINCESA ISABEL
01. Água Branca
05. Princesa Isabel
02. Imaculada
06. São José de Princesa
03. Juru
07. Tavares
04. Manaíra

I $2^{\mathrm{a}}$ REGIÃO GEOADMINISTRATIVA - Sede: ITABAIANA
0 I. Caldas Brandão
05. Itatuba
02. Gurinhém
06. Juarez Távora
03. Ingá
07. Juripiranga
04. Itabaiana
08. Mogeiro 
09. Pedras de Fogo

10. Pilar

I I. Riachão do Bacamarte

12. Salgado de São Félix
13. São José dos Ramos

14. São Miguel de Taipu

15. Serra Redonda

\section{I $3^{\text {a }}$ REGIÃO GEOADMINISTRATIVA - Sede: POMBAL}
01. Aparecida
02. Cajazeirinhas
03. Condado
04. Lagoa
05. Paulista

06. Pombal

07. São Bentinho

08. São Domingos de Pombal

09. Vista Serrana

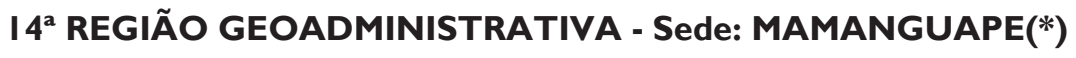

(*) Região criada e regulamentada pelo Projeto de Lei no 1.222/2009, de autoria do Deputado Estadual Rodrigo Soares, aprovado em 06.1 0.2009 na Assembleia Legislativa do Estado da Paraíba. Publicada como Lei No 8.950, de 04 de novembro de 2009, no Diário Oficial do Estado do dia 05 de novembro de 2009.
O I. Baía da Traição
07. Lagoa de Dentro
02. Capim
08. Mamanguape
03. Cuité de Mamanguape
09. Marcação
04. Curral de Cima
10. Mataraca
05. Itapororoca
| I. Pedro Régis
06. Jacaraú
12. Rio Tinto 
